\title{
Fitorreguladores e espectros de luz na micropropagação de Oncidium baueri Lindl
}

\author{
Phytoregulators and light spectrum in micropropagation Oncidium baueri Lindl
}

\author{
Samila Silva Camargo ${ }^{I^{*}}$ Daniele Brandstetter Rodrigues ${ }^{\mathrm{I}}$ Caroline Moreira Rodrigues $^{\mathrm{I}}$ \\ Adriane Marinho de Assis ${ }^{I}$ Ricardo Tadeu de Faria ${ }^{I I}$ Márcia Wullf Schuch ${ }^{I}$
}

\section{RESUMO}

Considerando que algumas espécies de orquideas estão ameaçadas de extinção, a micropropagação é uma alternativa para a produção de um grande número de mudas com qualidade, em curto espaço de tempo. Dentre os fatores que poderão interferir na eficácia dessa técnica, podem ser citados os fitorreguladores e o espectro da luz. Assim, o objetivo do trabalho foi verificar a multiplicação e o enraizamento in vitro da orquídea Oncidium baueri com uso de diferentes concentrações de fitorreguladores e distintos filtros modificadores da luz natural. Para a multiplicação dos explantes, foram avaliados dois fatores: diferentes concentrações de 6-benzilaminopurina (BAP) $(0,1,0$ e 2,0mg $L^{-1}$ ) e espectro de luz, com uso ou não de filtros (azul, vermelho, verde); no periodo de enraizamento, testaram-se duas concentrações de ácido indolbutírico (AIB) $\left(0\right.$ e $\left.0,1 \mathrm{mg} \mathrm{L}^{-1}\right)$ e os mesmos niveis de luz. Concluiu-se que, durante a multiplicação, a não utilização de BAP e filtros proporciona maior número de folhas, brotações e maior comprimento dessas brotações. Na etapa de enraizamento, obtiveram-se raizes mais desenvolvidas em meio de cultura com $0,1 \mathrm{mg} \mathrm{L}^{-1}$ de $A I B$.

Palavras-chave: Orchidaceae, $A I B, B A P$, multiplicação in vitro.

\section{ABSTRACT}

Judging from the fact that a few species of orchids are threatened with extinction, the micropropagation is an alternative to produce a bigger number of seedlings with high quality, in a shorter period of time. Among the factors that could interfere in the efficiency of this technique, some are the phytoregulators and the quality of the light. Thus, the objective of the research was to verify the multiplication and the rooting in vitro of the orchid Oncidium baueri using different concentrations of phytoregulators and distinct modifiers filters of natural light. Concerning the multiplication of the explants, two factors have been evaluated: different concentrations of 6-benzylaminopurine (BAP) (0, 1,0 and 2,0mg $\left.\mathrm{L}^{-1}\right)$ and light spectrum, with or without filters (blue, red, green); and in the period of rooting, two concentrations of indolebutyric acid (IBA) (0 and $\left.0,1 \mathrm{mg}^{-1}\right)$ and the same levels of light have been tested. It's possible to conclude that during the multiplication, not using BAP and filters provides a bigger number of leaves, more sprouting and bigger length of these sprouts. In the rooting phase, more developed roots were obtained in $0,1 m g L^{-1}$ de AIB culture.

Key words: Orchidaceae, IBA, BAP, multiplication in vitro.

\section{INTRODUÇÃO}

As orquídeas estão entre as plantas ornamentais mais apreciadas e apresentam grande potencial ornamental, devido, principalmente, à beleza e à diversidade de formas e cores de suas flores (FARIA et al., 2006). Não obstante o fato de serem membros da maior família de plantas com flores (Orchidaceae), muitas espécies de orquídeas estão ameaçadas de extinção (FERREIRA \& SUZUKI, 2008) e uma das causas se refere à forma como elas são propagadas. Em condições naturais, a multiplicação dessas plantas se dá pela proliferação de mudas laterais (brotações) ou pela disseminação natural das sementes, as quais são produzidas em cápsulas; porém, a baixa ou nula germinação de suas sementes na ausência de micorrizas interfere na eficácia da propagação em condições naturais, visto que tais sementes possuem pouca ou nenhuma reserva (FARIA et al., 2006; SOARES et al., 2010).

De acordo com SUZUKI \& FERREIRA (2007), a possibilidade de produzir orquídeas em

\footnotetext{
'Departamento de Fitotecnia, Faculdade de Agronomia Eliseu Maciel (FAEM), Universidade Federal de Pelotas (UFPEL), CP 354, 96010-900, Pelotas, RS, Brasil. E-mail: samilasc@yahoo.com.br. *Autor para correspondência.

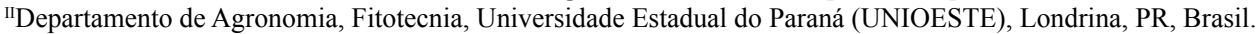


grandes quantidades poderá contribuir para a redução do risco de extinção de muitas espécies. Dessa forma, a micropropagação é uma alternativa para a produção de um elevado número de mudas em curto espaço de tempo, além de favorecer a qualidade fitossanitária delas, devido às condições controladas do ambiente no cultivo in vitro.

A propagação in vitro possibilita a obtenção de novas plantas através das fases de multiplicação e enraizamento. Entretanto, para o adequado desenvolvimento dos explantes, é necessário o controle dessas fases, já que são dependentes de vários fatores, como características intrínsecas da espécie, disponibilidade de luz, meio nutritivo utilizado e balanço hormonal, dentre os quais o último é um dos mais relevantes para o sucesso dessa técnica (PASA et al., 2012). SCHUCH \& ERIG (2005) descreveram que, além das formulações básicas dos meios de cultura normalmente utilizados, o emprego de fitorreguladores é imprescindível para o sucesso na propagação de culturas in vitro. $\mathrm{O}$ uso de BAP (6-benzilaminopurina) tem revelado eficiência no processo de multiplicação, tanto de estruturas aéreas como na indução de gemas adventícias em diversas espécies (LEITZKE et al., 2009). Já no enraizamento, o AIB (ácido indolbutírico) é o mais utilizado, pelo fato de essa auxina não causar fitotoxicidade aos explantes em uma larga faixa de concentração (IACONA \& MULEO, 2010).

Outro aspecto a ser considerado na micropropagação refere-se à utilização de lâmpadas fluorescentes utilizadas nas salas de crescimento e as modificações na formulação do meio de cultivo (ROCHA et al., 2007). No que se refere ao espectro da luz, a utilização de filtros em sala de cultivo possibilita a modificação no comprimento de onda das lâmpadas, com objetivo de favorecer o desenvolvimento dos explantes, aspecto este interessante no cultivo de orquídeas, já que, em germinação natural, estas necessitam de simbiose com fungos. A intensidade luminosa é de extrema importância para a colonização dos fungos nas raízes, já que influencia sua atividade fotossintética, como obtenção de glicose e outros produtos do hospedeiro, como os aminoácidos. Consequentemente, uma baixa luminosidade poderá resultar em menores taxas de colonização e esporulação que dependem da fotossensibilidade da espécie hospedeira (BAGYARAJ, 1991).

BRAGA et al. (2009) relataram que, com a variação no espectro da luz, pode-se manipular o crescimento in vitro de diversas espécies, de maneira alternativa à adição de fitorreguladores ao meio de cultura. Outros estudos têm demonstrado que o espectro da luz influencia a multiplicação e o enraizamento de explantes in vitro (IACONA \& MULEO, 2010) e, segundo ERIG \& SCHUCH (2005), afeta a eficiência biológica dos fitorreguladores adicionados ao meio de cultura, bem como o balanço hormonal nos tecidos.

No entanto, estudos a respeito do espectro de luz na micropropagação de orquídeas são escassos e também não são claros os efeitos do espectro e de níveis de irradiância no crescimento de plântulas durante o cultivo in vitro.

Tendo em vista esses aspectos, o objetivo do trabalho foi avaliar a multiplicação e o enraizamento in vitro da orquídea Oncidium baueri, sob diferentes concentrações de fitorreguladores, com uso de distintos filtros modificadores da luz natural.

\section{MATERIAL E MÉTODOS}

O trabalho foi realizado no período de outubro de 2013 a maio de 2014. As plântulas de Oncidium baueri deste estudo foram oriundas da germinação in vitro de sementes, realizada na Universidade Estadual de Londrina (UEL). Quando utilizadas, apresentavam seis meses de cultivo in vitro, com $5,0 \pm 0,3 \mathrm{~cm}$ de parte aérea e destas foram retirados explantes com aproximadamente $2,0 \mathrm{~cm}$ de comprimento, sem a presença de raízes.

$\mathrm{Na}$ primeira etapa do experimento, que se refere à multiplicação dos explantes, foram avaliados dois fatores: concentrações de 6-benzilaminopurina (BAP) $\left(0,1,0\right.$ e $\left.2,0 \mathrm{mg} \mathrm{L}^{-1}\right)$ e espectro de luz, com o uso ou não de filtros de acetato celulose - LEE Filters - Central Way, Walworth Ind. Estate, Andover, Hampshire SP10 5AN, England - (azul: número 724 - Ocean Blue, com $36,20 \%$ de transmitância; vermelho: número 106 - Primary red, com 9,32\% de transmitância; verde: número 738 Jasgreen, com 52,33\% de transmitância; e, testemunha, sem uso de filtro, totalizando 12 tratamentos, com quatro repetições, sendo utilizados cinco explantes em cada repetição. Para o enraizamento, os explantes foram mantidos com folhas e foram testadas duas concentrações de ácido indolbutírico (AIB) (0 e 0,1mg $\mathrm{L}^{-1}$ ), único fitorregulador adicionado ao meio de cultivo, e os quatro níveis de luz já descritos, totalizando oito tratamentos, com quatro repetições e cinco explantes em cada repetição. Dessa forma, o estudo foi representado por 80 frascos, 48 frascos no processo de multiplicação e no enraizamento, 32 frascos.

Em ambos os experimentos, os explantes com $2 \mathrm{~cm}$ de parte aérea foram transferidos para frascos de vidro de $250 \mathrm{~mL}$, com $30 \mathrm{~mL}$ do meio de cultivo indicado para a cultura: MS (MURASHIGE \& 
SKOOG, 1962), composto por seus sais e vitaminas estabelecidos, $100 \mathrm{mg} \mathrm{L}^{-1}$ mio-inositol e $30 \mathrm{~g} \mathrm{~L}^{-1}$ de sacarose e ainda, de acordo com o tratamento, o acréscimo dos fitorreguladores BAP e AIB, para a multiplicação e o enraizamento, respectivamente. Posteriormente, o $\mathrm{pH}$ foi ajustado para 5,8 antes da inclusão do ágar na concentração de $6,0 \mathrm{~g} \mathrm{~L}^{-1}$, e, em seguida, realizou-se a autoclavagem dos meios de cultura a $120^{\circ} \mathrm{C}$ e $1,5 \mathrm{~atm}$ de pressão, por 20 minutos. Assim, os frascos foram mantidos em sala de crescimento, com fotoperíodo de 16 horas, temperatura de $25 \pm 2^{\circ} \mathrm{C}$ e intensidade luminosa de $27 \mu \mathrm{mol} \mathrm{m} \mathrm{m}^{-2}$.

Seis meses após a incubação dos explantes, as variáveis avaliadas no experimento de multiplicação foram: número de folhas e brotações; comprimento da parte aérea $(\mathrm{cm})$ e da maior brotação (cm); e, no enraizamento, avaliou-se o número de raízes e o comprimento da maior raiz $(\mathrm{cm})$.

Nos dois estudos, o delineamento experimental utilizado foi inteiramente casualizado e os dados foram submetidos à análise de variância com aplicação do teste $\mathrm{F}$ e as médias, quando significativas estatisticamente, comparadas pelo teste de Tukey a $5 \%$ de probabilidade, através do programa estatístico WINSTAT (MACHADO \& CONCEIÇÃO, 2007). As variáveis discretas, provenientes de contagem (número), foram transformadas na $\sqrt{ }(x+0,5)$, onde $x$ é o percentual obtido de cada variável.

\section{RESULTADOS E DISCUSSÃO}

Nas etapas de multiplicação e enraizamento dos explantes, houve interação entre os fatores estudados (concentração de BAP e espectro de luz; concentração de AIB e espectro de luz) para todas as variáveis (Tabela 1, 2 e 3). Na fase de multiplicação, foram observadas plântulas com maior número de folhas na ausência de BAP e na concentração de 2,0mg L $\mathrm{m}^{-1}$ (Tabela 1), e ainda, sem a necessidade de uso de filtros modificadores da luz natural. Em contra partida, ARAÚJO et al. (2009) verificaram que o maior número de folhas foi registrado em plantas de Cattleya loddigesii, cultivadas sob filtro azul, contrariando esse estudo, onde a ausência de filtro proporcionou resultados mais satisfatórios.

Em relação ao número de brotações, verificou-se que o uso de $2,0 \mathrm{mg} \mathrm{L}^{-1}$ de BAP e do filtro azul, assim como o tratamento testemunha (sem filtro e sem BAP), favorecem a emissão de mais brotações (Tabela 1). Resultados semelhantes foram encontrados por ARAÚJO et al. (2006), os quais, avaliando a multiplicação da mesma orquídea, obtiveram maior quantidade de brotações na ausência de BAP. Também SUZUKI et al. (2004), que, trabalhando com Cattleya fimbriatum, verificaram o aumento do número de brotações na ausência de BAP.

ERIG \& SCHUCH (2006) registraram que o cultivo de macieira (Malus domestica Borkh) sob celofane vermelho em sala de crescimento, com $1 \mathrm{mg} \mathrm{L}^{-1}$ de BAP adicionado ao meio de cultura possibilitou a obtenção de maior número de gemas e taxa de multiplicação nas cultivares 'Matergala' e 'Galaxy' e, consequentemente, maior número de folhas. Por outro lado, ERIG \& SCHUCH (2005), em estudo com framboeseira (Rubus idaeus L.), verificaram que o maior número de brotos foi obtido com as luzes verde e vermelha.

Verifica-se, neste estudo, que, quanto ao comprimento da parte aérea, os explantes mantidos sob luz verde, sem BAP, e também em luz verde e vermelha com $2 \mathrm{mg} \mathrm{L}^{-1}$ de BAP foram os que apresentaram as maiores médias (Tabela 2). $\mathrm{O}$ efeito benéfico do filtro vermelho também foi relatado por ARAÚJO et al. (2009), quando os explantes da orquídea Cattleya loddigesii Lindl apresentaram maior crescimento em altura sob cultivo em celofane vermelho. Em experimento com maçã 'Galaxy' e

Tabela 1 - Número de folhas (NF) e brotações (NB) em explantes de orquídeas Oncidium baueri, na etapa de multiplicação in vitro, após um período de seis meses. Pelotas - RS, 2014.

\begin{tabular}{|c|c|c|c|c|c|c|c|c|c|c|c|c|c|}
\hline \multirow{6}{*}{ Filtros } & \multirow[b]{2}{*}{ Sem } & \multicolumn{2}{|c|}{--------- 0 --------- } & \multicolumn{2}{|c|}{-------- 1,0 -------- } & \multicolumn{2}{|c|}{-------- 2,0 -------- } & \multicolumn{2}{|c|}{--------- 0 ---------- } & \multicolumn{2}{|c|}{-------- 1,0 -------- } & \multicolumn{2}{|c|}{------- 2,0 ------ } \\
\hline & & 4,84 & $\mathrm{Aa}^{*}$ & 3,30 & $\mathrm{Bb}$ & 5,03 & $\mathrm{Aa}$ & 1,87 & $\mathrm{Aa}$ & 1,51 & $\mathrm{Ba}$ & 1,55 & $\mathrm{Bb}$ \\
\hline & Vermelho & 3,90 & Ac & 2,34 & $\mathrm{Cc}$ & 3,53 & $\mathrm{Bb}$ & 1,51 & $\mathrm{Ab}$ & 1,22 & $\mathrm{Bc}$ & 1,25 & $\mathrm{Bc}$ \\
\hline & Verde & 4,41 & $\mathrm{Ab}$ & 3,73 & $\mathrm{Ba}$ & 3,85 & $\mathrm{Bb}$ & 1,22 & $\mathrm{Cc}$ & 1,35 & $\mathrm{Bb}$ & 1,49 & $\mathrm{Ab}$ \\
\hline & Azul & 2,74 & $\mathrm{Bd}$ & 3,00 & $\mathrm{ABb}$ & 3,08 & Ac & 1,24 & $\mathrm{Cc}$ & 1,58 & $\mathrm{Ba}$ & 1,87 & $\mathrm{Aa}$ \\
\hline & CV (\%) & \multicolumn{6}{|c|}{12,84} & \multicolumn{6}{|c|}{9,47} \\
\hline
\end{tabular}

${ }^{*}$ Médias seguidas de mesma letra, minúscula na coluna e maiúscula na linha, não diferem entre si pelo Teste de Tukey, em nível de 5\% de probabilidade de erro. 
Tabela 2 - Comprimento da parte aérea (CPA) e da maior brotação (CMB) em explantes de orquídeas Oncidium baueri, na etapa de multiplicação in vitro, após um período de seis meses. Pelotas - RS, 2014.

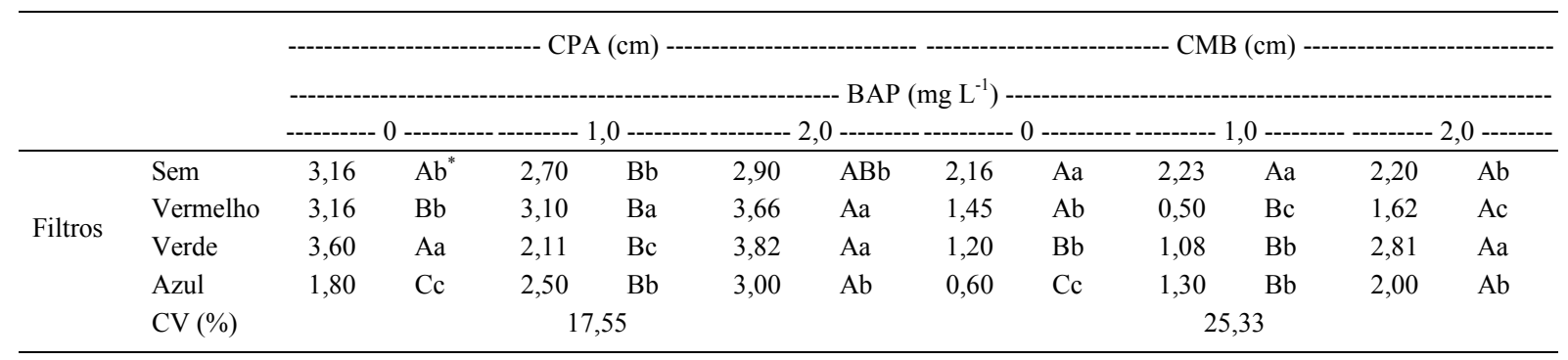

*Médias seguidas de mesma letra, minúscula na coluna e maiúscula na linha, não diferem entre si pelo Teste de Tukey, em nível de 5\% de probabilidade de erro.

'Mastergala', ERIG \& SCHUCH (2006) constataram que, independentemente da luz utilizada, os melhores resultados foram obtidos utilizando BAP no meio de cultura, indicando que esta substância é indispensável na superação da dominância apical e no aumento da taxa de multiplicação e crescimento das brotações.

Para o comprimento da maior brotação, independente da concentração de BAP, a não utilização de filtro, assim como o uso de filtro verde, acrescido de $2 \mathrm{mg} \mathrm{L}^{-1}$ de BAP, foram os tratamentos que propiciaram as maiores médias (Tabela 2). Resultados distintos foram encontrados por ERIG \& SCHUCH (2006), que registraram melhores resultados para número e comprimento de brotações na cv. 'Mastergala' de macieira sob cultivo em celofane amarelo, já na cv. 'Galaxy', o espectro de luz não alterou esse parâmetro. Em relação à utilização das citocininas, SANTOS et al. (2010), em estudo com as orquídeas Epidendrum ibaguense, verificaram que o maior comprimento das brotações foi observado com o aumento na concentração de BAP e o menor comprimento foi verificado no tratamento controle.
Entretanto, no presente estudo, mesmo na ausência de BAP e sem uso de filtros modificadores da luz natural, constataram-se brotações de maior comprimento.

Na segunda etapa deste estudo, durante o enraizamento dos explantes da orquídea $\boldsymbol{O}$. baueri (Tabela 3), para a variável número de raízes, a utilização de $0,1 \mathrm{mg} \mathrm{L}^{-1}$ de AIB na ausência de filtro ou com uso de filtro verde sem AIB, foram registradas as maiores médias, ou seja, explantes com mais raízes; embora o uso de filtro verde sem AIB não tenha diferido estatisticamente dos demais tratamentos em que foram utilizados filtro na ausência de AIB. Em experimento similar com a orquídea Epidendrum ibaguense, SANTOS et al. (2010) concluíram que as auxinas geralmente induzem a formação e o desenvolvimento de raízes, o que também se verificou neste experimento. Entretanto, a presença de raízes foi constatada mesmo naquelas plântulas mantidas em meio de cultura sem o fitorregulador.

Considerando o comprimento das raízes, as maiores $(1,37 \mathrm{~cm})$ foram obtidas com uso de $0,1 \mathrm{mg} \mathrm{L}^{-1}$ de AIB com filtro vermelho, sem diferença

Tabela 3 - Número de raízes (NR) e comprimento da maior raiz (CMR) em explantes de orquídeas Oncidium baueri, na etapa de enraizamento in vitro, após um período de seis meses. Pelotas - RS, 2014.

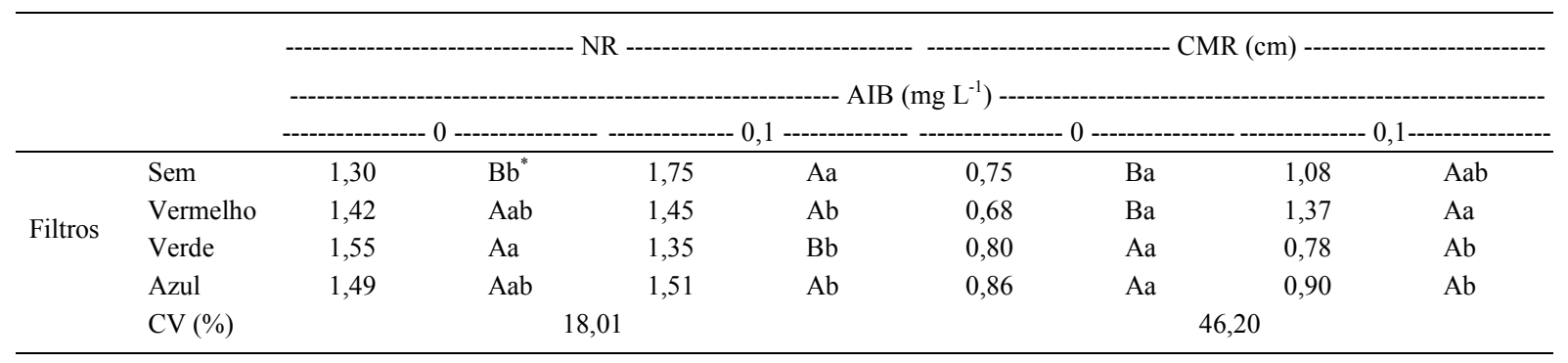

*Médias seguidas de mesma letra, minúscula na coluna e maiúscula na linha, não diferem entre si pelo Teste de Tukey, em nível de 5\% de probabilidade de erro.

Ciência Rural, v.45, n.11, nov, 2015. 
estatística do tratamento $0,1 \mathrm{mg} \mathrm{L}^{-1}$ de $\mathrm{AIB}$, sem a utilização de filtro. RAI \& MISRA (2005), em estudo com a micropropagação de Carissa carandas L., observaram que o AIB não resultou em enraizamento satisfatório, distintamente, ANTONOPOLOU et al. (2004), descreveram que os melhores resultados nos parâmetros de enraizamento em orquídeas Cattleya loddigesii foram observados sob radiação branca, uma vez que esse tipo de radiação contém todos os comprimentos de onda necessários para ganhos energéticos pela fotossíntese, bem como para outros processos fisiológicos.

Em síntese, diante de pequenas diferenças constatadas no período de multiplicação, justifica-se a utilização do meio de cultura sem o BAP e ainda não há a necessidade do uso de filtros modificadores da luz natural. Na fase de enraizamento, é possível obter raízes com número e desenvolvimento adequados, a utilização do meio de cultura MS com $0,1 \mathrm{mg} \mathrm{L}^{-1}$ de AIB e sem o uso de filtros coloridos é o mais indicado. Salienta-se a importância da não utilização dos fitorreguladores e filtros, uma vez que tais procedimentos possibilitam a redução nos custos de produção das mudas.

\section{CONCLUSÃO}

A multiplicação in vitro dos explantes de Oncidium baueri pode ser realizada em meio de cultura MS sem BAP e sem a utilização de filtros nas cores vermelho, verde e azul. Para o enraizamento in vitro de Oncidium baueri, a utilização de meio de cultura MS com $0,1 \mathrm{mg} \mathrm{L}^{-1}$ de AIB e sem o uso de filtros coloridos é o mais indicado.

\section{AGRADECIMENTOS}

À Coordenação de Aperfeiçoamento de Pessoal de Nível Superior (CAPES), pelo apoio financeiro e concessão das bolsas de estudo.

\section{REFERÊNCIAS}

ANTONOPOLOU, C. et al. The influence of radiation quality on the in vitro rooting and nutrient concentrations of peach rootstock. Biologia Plantarum, v.48, p.549-553, 2004. Disponível em: $<$ http://link.springer.com/article/10.1023\%2FB\%3ABIOP.00000 47151.26284.5f/lookinside/000.png>. Acesso em: 20 mar. 2014. doi: 10.1023/B:BIOP. 0000047151.26284.5f.

ARAÚJO, A.G. et al. Crescimento in vitro de Cattleya loddigesii Lindl. em diferentes espectros luminosos associados com ácido giberélico. Revista Ceres, v.56, n.5, p.542-546, 2009. Disponível em: <http://www.ceres.ufv.br/ceres/revistas/V56N005P07807.pdf>. Acesso em: 16 mar. 2015.
ARAUJO, A.G. et al. Propagação in vitro de plântulas de orquídea em diferentes meios de cultura e concentrações de citocinina. Plant Cell Culture \& Micropropagation, v.2, n.2, p.68-73, 2006. Disponível em: $<$ http://www.abctp.ufla.br/v2n2.pdf $>$. Acesso em: 08 jan. 2014.

BAGYARAJ, D.J. Ecology of vesicular-arbuscular mycorrhizae. In: ARORA, D.K. et al. (Eds.). Handbook of applied micology: soil and plant. New York: Marcel Dekker, 1991. V.1, p.4-34.

ERIG, A.C.; SCHUCH, M.W. Ação da 6-Benzilaminopurina e da qualidade da luz na multiplicação in vitro de macieira (Malus domestica Borkh.) cvs. 'Galaxy' e 'Mastergala'. Revista Brasileira de Agrociência, v.12, n.2, p.151-155, 2006. Disponível em: <http://periodicos.ufpel.edu.br/ojs2/index.php/CAST/article/ viewFile/4511/3379>. Acesso em: 18 maio 2014.

ERIG, A.C.; SCHUCH, M.W. Tipo de luz na multiplicação in vitro de framboeseira (Rubus idaeus L.) 'Batum'. Revista Brasileira de Fruticultura, v.27, n.3, p.488-490, 2005. Disponível em: <http://www.scielo.br/scielo.php?pid=S010029452005000300035\&script=sci_arttext $>$. Acesso em: 30 jul. 2014. doi: 10.1590/S0100-29452005000300035.

FARIA, R.T. et al. Propagação in vitro de Oncidium baueri Lindl. (Orchidaceae) sem uso de agar. Acta Scientific Agronomy, v.28, n.1, p.7174, 2006. Disponível em: <http://periodicos.uem.br/ojs/ index.php/ActaSciAgron/article/view/1672/1040>. Acesso em: 16 jul. 2014. doi: 10.4025 /actasciagron.v28i1.1672.

FERREIRA, W.M.; SUZUKI, R.M. O cultivo in vitro de orquídeas como alternativa para a preservação de espécies nativas ameaçadas de extinção. In: LOIOLA, M.I.B. et al. (Org.). Atualidades, desafios e perspectiva da botânica no Brasil. Natal: Imagem Gráfica, 2008. p.67-68.

IACONA, C.; MULEO, R. Light quality affects in vitro adventitious rooting and ex vitro performance of cherry rootstock colt. Scientia Horticulturae, v.125, p.630-636, 2010. Disponível em: <http://www.researchgate.net/publication/248477981_Light_ quality_affects_in_vitro_adventitious_rooting_and_ex_vitro performance_of_cherry_rootstock_Colt $>$. Acesso em: 01 out. 2014. doi: $10.1016 /$ j.scienta.2010.05.018.

LEITZKE, L.N. et al. Meio de cultura, concentração de AIB e tempo de cultivo no enraizamento in vitro de amora-preta e framboeseira. Revista Brasileira de Fruticultura, v.31, n.2, p.582-587, 2009. Disponível em: <http://www.scielo.br/scielo. php?pid $=S 010029452009000200037 \&$ script $=$ sci_arttext $>$. Acesso em: 02 mar. 2014. doi: 10.1590/S0100-29452009000200037.

MACHADO, A.A.; CONCEIÇÃO, A.R. Sistema de análise estatística para Windows. Winstat. Pelotas: UFPel, 2007. Versão 2.0.

MURASHIGE, T.; SKOOG, F. A revised medium for rapid growth and biossay with tabacco tissue cultures. Physiologia Plantarum, v.15, p.473-497, 1962.

PASA, M. da S. et al. Qualidade de luz e fitorreguladores na multiplicação e enraizamento in vitro da amoreira-preta 'Xavante'. Ciência Rural, v.42, n.8, p.1392-1396, 2012. Disponível em: $<$ http://www.scielo.br/scielo.php?script=sci_arttext\&pid=S0103$84782012000800010 \& \operatorname{lng}=\mathrm{pt} \& \mathrm{nrm}=\mathrm{iso} \& \ln \mathrm{g}=\mathrm{en}>$. Acesso em: 02 mar. 2014. doi: 10.1590/S0103-84782012000800010.

RAI, R.; MISRA, K.K. Micropropagation of Karonda (Carissa carandas) through shoot multiplication. Scientia Horticulturae, 
v.103, n.2, p.227-232, 2005 Disponível em: <http://www. researchgate.net/publication/241091575_Micropropagation_of Karonda_(_Carissa_carandas)_through_shoot_multiplication $>$. Acesso em: 18 maio 2014. doi: 0.1016/j.scienta.2003.09.005.

ROCHA H.S. et al. Propagação in vitro de bananeira 'Prata Anã' (AAB): intensidades luminosas e concentrações de sacarose nas fases de multiplicação e enraizamento. Plant Cell Culture \& Micropropagation, v.3, p.10-16, 2007. Disponível em: <http:// www.abctp.ufla.br/v3n1.pdf>. Acesso em: 02 mar. 2014.

SANTOS, M.R.A. et al. BAP e AIB no cultivo in vitro de Epidendrum ibaguense KUNTH. Plant Cell Culture \& Micropropagation, v.6, n.2, p.90-98, 2010. Disponível em: $<$ http://www.abctp.ufla.br/v6n2.pdf $>$. Acesso em: 18 ago. 2014.

SCHUCH, M.W.; ERIG, A.C. Micropropagação de plantas frutíferas. In: FACHINELLO, J.C. et al. Propagação de plantas frutíferas. Brasília: DF: Embrapa Informação Tecnológica, 2005. p.155-173.
SOARES, J.D.R. et al. Estiolamento e luz artificial no cultivo in vitro de orquídeas nativa e híbrida. Ciência Rural, v.40, n.9, p. 1941-1947, 2010. Disponível em: <http://www.scielo.br/scielo. php script $=$ sci_arttext\&pid $=$ S0103-84782010000900014>. Acesso em: 19 set. 2014. doi: 10.1590/S0103-84782010005000146.

SUZUKI, R.M. et al. Endogenous hormonal levels and growth of dark-incubated shoots of Catasetum fimbriatum. Journal of Plant Physiology, v.161, p.929-935, 2004. Disponível em: $<$ http://www.researchgate.net/publication/8331392_Endogenous_ hormonal_levels_and_growth_of_dark-incubated_shoots_of Catasetum_fimbriatum $>$. Acesso em: 15 jul. 2014. doi: $0.10 \overline{1} 6 \overline{\mathrm{j}}$. jplph.2003.11.001.

SUZUKI, R.M.; FERREIRA, W.M. Introdução às técnicas de micropropagação de orquídeas. In: BARBOSA, L.M.; SANTOS JR., N.A. (Orgs.). A Botânica no Brasil: pesquisa, ensino e políticas públicas ambientais. São Paulo: Imprensa Oficial, 2007. p.655-659.

Ciência Rural, v.45, n.11, nov, 2015. 